\title{
CAN GOLD EFFECTIVELY HEDGE RISKS OF EXCHANGE RATE?
}

\author{
Kuan-Min Wang \\ Department of Finance, Overseas Chinese University, Taichuang, Taiwan \\ E-mail:wkminn@ocu.edu.tw
}

Received 13 September 2011; accepted 23 February 2012

\begin{abstract}
This study tests whether gold can effectively hedge exchange rate risks. We take into account the asymmetric characteristic of exchange rate fluctuations and use the dynamic panel threshold model in order to select gold prices in major gold-related currencies in the world: the Australian dollar, the Canadian dollar, the euro, the Indian rupee, the Japanese yen, the South African rand, and the British pound. Using monthly data from January 1999 to January 2010, with lagged one-period exchange rate returns (US dollar depreciation rate) as the threshold variable, the estimation results suggest that there are two thresholds at $-7.5 \%$ and $-3.7 \%$. These can be divided into regime 1 (exchange rate returns $\leq-7.5 \%)$, regime $2(-7.5 \%<$ exchange rate returns $\leq-3.7 \%$ ), and regime 3 (exchange rate returns $>-3.7 \%$ ). Regarding the effectiveness of gold hedging, regime 2 is higher than is regime 3 . The risk hedging effect of regime 1 is not significant because it might be caused by the excessive devaluation of the US dollar in the short-term and the overshooting of the exchange rate adjustment, making gold unable to hedge the devaluation risks of the US dollar.
\end{abstract}

Keywords: gold price, exchange rate hedge, asymmetric effect, dynamic panel threshold model.

Reference to this paper should be made as follows: Wang, K.-M. 2013. Can gold effectively hedge risks of exchange rate?, Journal of Business Economics and Management 14(5): 833-851.

JEL Classification: C23, F31, F33.

\section{Introduction}

Since 2009, fuelled by the capital market, gold price quotes have frequently surprised by traders. After successfully reaching the landmark 1000 US dollar/ounce in that year, record high prices have continued to be set. The average gold price in October 2010 reached more than 1342 US dollar/ounce. Figure 1 indicates the large growth rate from 1971 to 1980 as gold prices reached a then-record high of 873 US dollar/ounce, which was the equivalent to 2287 US dollar/ounce after adjusting for inflation. The recent gold price rally lasted from 2004 to 2010 .

Since the depreciation of the US dollar in 2010, the depreciation expectations of other national currencies have been strong. In response, investors keep buying gold, making 


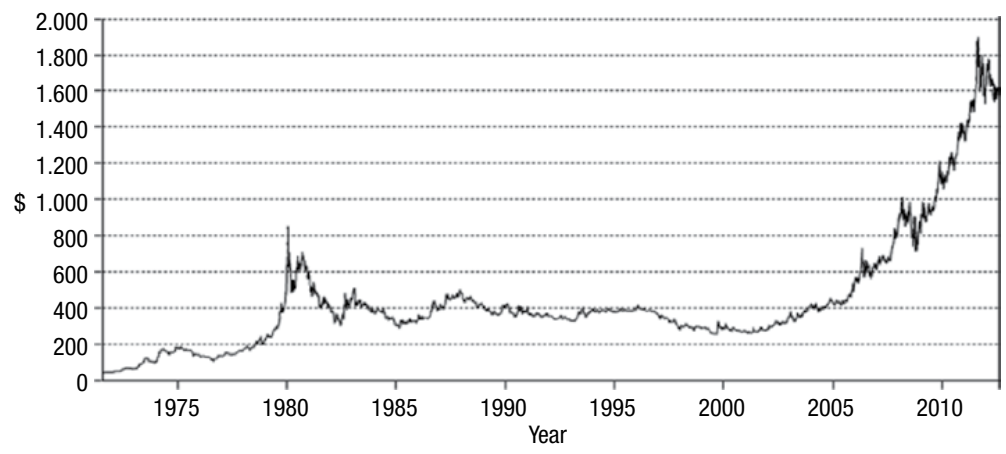

Fig. 1. The trend of gold price, US dollar per ounce Source: World Gold Council, www.gold.org

international gold prices continuously set new records. Most investors believe that the bullish market for gold is not finished and that the gold price will exceed 2000 US dollar/ounce in the future. International gold prices and US dollar trends have a negatively correlated relationship.

The main reason why investors include gold in their asset portfolios is that other financial assets such as stocks and bonds have no risk-aversion capabilities because of the reduction in purchasing power owing to national currency devaluation. Hence, if gold can hedge foreign exchange risks, adding gold into asset portfolios can make them more efficient.

The aversion of foreign exchange rate fluctuations using gold has two implications. One is that gold can offset changes in the domestic purchasing power of a national currency. In other words, when the domestic composite price index rises, the gold price in the local currency will increase by the same proportion, which is known as the perfect internal hedge. If the proportion is smaller than one, this is known as the partial internal hedge. The other implication is that the increasing proportion of the gold price in the domestic currency is equivalent to the decreasing proportion of the exchange rate in the domestic currency compared with the per unit foreign currency, which is known as the perfect external hedge. Similarly, if the proportion is smaller than one, this is the partial external hedge. This study is concerned with the first implication.

Previous studies of gold prices and relevant models can be categorized into three groups. The first type discussed the relationship between gold prices and macroeconomic variables such as exchange rate, interest rate, and income (e.g. Dooley et al. 1995; Sjaastad, Scacciavillani 1996; Sjaastad 2008). The second type discussed the factors affecting gold price fluctuations (e.g. Baker, Van Tassel 1985; Koutsoyiannis 1983; Pindyck 1993). The third type discussed the long-term and short-term relationships between gold prices and the general price index as well as the effectiveness of gold in avoiding the risks of inflation (e.g. Kolluri 1981; Laurent 1994; Mahdavi, Zhou 1997; Moore 1990). Regarding the first category, most studies of the relationship between gold prices and macroeconomic variables have focused on time series, mainly the linear 
ones such as the studies by Sjaastad and Scacciavillani (1996), Capie et al. (2005) and Sjaastad (2008). The disadvantage of using linear models is that they cannot predict the relationships between variables in different situations. For example, the rise and fall of exchange rates may trigger changes in the relationship between variables.

Kyrtsou and Labys (2006) pointed out that if a nonlinear relationship is confirmed between variables, measurement errors may occur by using linear models. Fluctuation clusters can occur in financial variable data, which means that nonlinear phenomena such as jumps and cycles may exist. Hence, empirical estimations may be biased if they are not considered in the measurement models. Wang et al. (2011) used nonlinear models in order to test the effectiveness of using gold to avoid inflation rate risk in Japan and the US, finding that the price rigidity adjustment characteristics caused by transaction costs may affect the anti-inflation effect of gold. Wang and Lee (2011) also found that the asymmetry caused by exchange rate fluctuations in Japan affected the effectiveness of gold in avoiding the risks of yen depreciation.

Baur and Lucey (2010) studied the constant and time-varying relationships between stocks, bonds, and gold in order to investigate the existence of a hedge and a safe haven. They found that (i) gold is used as a hedge against stocks, (ii) gold is a safe haven in extreme stock market conditions, and (iii) gold is only a safe haven for stocks for 15 trading days after an extreme shock has occurred. Moreover, Joy (2011) found that (i) over the past 23 years gold has behaved as a hedge against the US dollar, (ii) gold has been a poor safe haven, and (iii) in recent years, gold has acted increasingly as an effective hedge against currency risk associated with the US dollar. Pukthuanthong and Roll (2011) considered that the price of gold can be associated with currency depreciation in every country and that the dollar (euro, pound, yen) price of gold can be related to dollar (euro, pound, yen) depreciation. However, the abovementioned studies offer limited empirical explanations because time-series models were used to analyse only individual countries. Hence, multinational analysis could fully explain the hedging characteristics of gold.

In order to understand the relationship between gold prices and the exchange rate, the most direct approach is to start from the understanding of currency devaluation. Many factors affect currency devaluation; for example, inflation causes currency devaluation and a fall in the nominal prices of domestic assets. Because the gold price can reflect inflation and because it is rapidly adjustable, only gold can maintain its value compared with other assets. However, the relationship between gold prices and the exchange rate is subject to information asymmetry because of special economic factors and countryspecific factors such as market competition and transaction costs. If the relationship between gold prices and the exchange rate can be estimated by nonlinear models, more information about using gold to effectively hedge exchange rate fluctuations can be provided to investors.

The main purpose of this study is to test whether gold can effectively hedge exchange rate risks, namely whether gold can offset changes in the domestic purchasing power of a currency in the case of depreciation. This study uses the general equilibrium gold 
pricing model and dynamic panel threshold model (DPTM) for multinational analysis and validation.

This study takes into account the asymmetric characteristics of exchange rate changes and uses the DPTM in order to select gold prices in major gold-related currencies in the world: the Australian dollar, the Canadian dollar, the euro, the Indian rupee, the Japanese yen, the South African rand, and the pound. The empirical results suggest that there are two thresholds (three regimes) at $-7.5 \%$ and $-3.7 \%$, divided into regime 1 (exchange rate returns $\leq-7.5 \%)$, regime $2(-7.5 \%<$ exchange rate returns $\leq-3.7 \%)$, and regime 3 (exchange rate returns $>-3.7 \%$ ). Regarding the effectiveness of gold hedging, regime 2 is higher than is regime 3 . The risk hedging effect of regime 1 is not significant because it might be caused by the excessive devaluation of the US dollar in the short-term and the overshooting of the exchange rate adjustment, making gold unable to hedge the devaluation risks of the US dollar.

The main implication of the use of nonlinear models and multinational panel data in this study is to further expand the concept of exchange rate fluctuations. Coupled with the DPTM, the validation approach has never before been attempted and this is the major innovation of this study.

\section{Simple model}

We follow Wang and Lee (2011), Clements and Fry (2008) to specify the model. Following Wang and Lee (2011), we develop a simple model for the global gold market in which the purchasing power parity (PPP) theory holds for gold prices but not for the prices of general commodities. We assume that the world market clears continuously and that arbitrage makes prices satisfy the relative PPP. The model is specified as follows:

$$
Q^{s}=Q^{s}(G / P), Q^{d}=Q^{d}\left(G^{*} / P^{*}\right), Q^{s}=Q^{d}, G=E G^{*}(1+X),
$$

where $Q^{s}$ is the quantity supplied of gold; $G$ is the domestic currency's denominated gold price; $P$ is the home country's general cost index; $Q^{d}$ is the quantity consumed; $G^{*} / P^{*}$ is the relative price incurred by foreign consumers; $E$ is the spot exchange rate (in terms of a unit of foreign currency); and $X$ represents the 'spread' between domestic and foreign prices, which is taken to be a constant. Taking the total difference of the equations in (1), using a hat ("^") to denote the proportional change $(\hat{Z}=\Delta Z / Z)$, employing $\varphi$ to denote the price elasticity of supply, and using $\vartheta$ to denote the price elasticity of demand, one can obtain the solution to the model as:

$$
\hat{G}^{*} / P^{*}=\delta \hat{R},
$$

where $\delta=\phi /(\phi-\vartheta)$ is the share of supply in the excess supply elasticity and $R=P / E P^{*}$ is the real exchange rate, defined such that an increase in $R$ represents a real appreciation of the currency of the domestic (or producing) country. If supply elasticity $\phi \geq 0$ and the demand elasticity $\vartheta \leq 0$, it follows that $0 \leq \delta \leq 1$.

Equation (2) is the fundamental pricing rule for gold. It states that the change in the world relative price of gold is a positive fraction, $\delta$, of the change in the real value 
of the domestic currency. The link between the domestic and foreign nominal prices of gold is provided by the PPP relation. For simplicity, we set the spread, $X$, equal to zero, which yields $G=E G^{*}$. Dividing both sides of this equation by $\mathrm{P}$ and utilizing the relationship that $R=P / E P^{*}$, we then obtain $G^{*} / P^{*}=R(G / P)$. This equation provides a link between domestic and foreign relative prices, so it can be considered to be a real version of PPP.

The interactions between the exchange rate and gold prices are presented in Figure 2. The DD' curve is the locus of the world and domestic gold prices when the global gold market clears. The DD' curve is downward sloping, which indicates that an increase in the domestic price stimulates imports or production. According to the above set, for the market to be clear, the trade deficit or excess supply has to be offset by a reduction in the world price in order to stimulate the demand. The clearing of the gold market implies that $\phi(\hat{G}-\hat{P})=\vartheta\left(\hat{G}^{*}-\hat{P}^{*}\right)$, so

$$
\hat{G}^{*} / P^{*}=(\phi / \vartheta)(\hat{G} / G)=-[\delta /(1-\delta)](\hat{G} / G),
$$

where $[-\delta /(1-\delta)]<0$ is the elasticity of the DD' curve, $G^{*} / P^{*}=R(G / P)$. The domestic and foreign prices of gold are linked by the real PPP relationship as discussed above. This relationship is depicted in Figure 2 as the OA line whose slope is R. In order to achieve general equilibrium, the market must simultaneously locate on both DD' and $\mathrm{OA}$, namely the market must be located at the intersection point, b0, of these two lines. A depreciation of the domestic currency causes the OA line to flatten and tilt from OA to $\mathrm{OB}$, so the equilibrium point changes from $\mathrm{b} 0$ to $\mathrm{b} 1$, which causes the world price $G^{*} / P^{*}$ to fall and domestic price $G / P$ to rise.

From equations (2), (4), and the relationship $R=P / E P^{*}$, we can further derive the link between the fluctuations in gold prices and the exchange rate, ceteris paribus, is

$$
\hat{G}=\mathrm{f}(\hat{\mathrm{E}}) \text {. }
$$

Following equation (4), we specify the model as no contemporaneous correlations:

$$
\Delta g_{t}=f\left(\Delta e_{t-i}\right)
$$

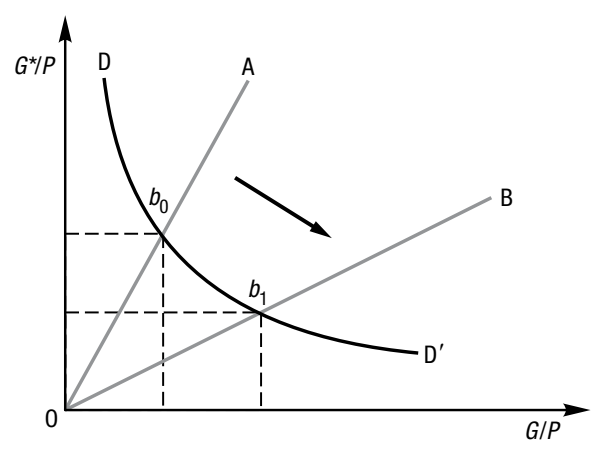

Fig. 2. Impact of currency depreciation on gold price 
$\Delta e_{t-i}=\ln \left(e_{t-i} / e_{t-i-1}\right) \times 100$ denotes the returns of $e_{t-i}$ and $\Delta g_{t}=\ln \left(g_{t} / g_{t-1}\right) \times 100$ denotes gold returns. When $f^{\prime}>0$, gold returns are high enough to compensate for the loss caused by the change in the domestic currency's internal purchasing power. When the domestic currency depreciates ( $\Delta e_{t-i}$ positive), the domestic currency denominated price of gold rises. If the gold price rises less than $\Delta e_{t-i}$ does, this is the case of an incomplete hedge; if the gold price increases more than $\Delta e_{t-i}$ does, this is the case of a complete hedge. In addition, when there is imperfect market competition or transaction costs caused by the monetary authority's intervention, there is an asymmetric adjustment between gold returns and exchange rate returns. This asymmetry adjustment is mainly affected by the relative size of the transaction cost of exchange rate fluctuations. Depending on the status of $\Delta e_{t-d}$, equation (6) is specified as follows:

$$
\Delta g_{t}= \begin{cases}f_{1}\left(\Delta e_{t-i}\right) & \Delta e_{t-d}>\gamma \\ f_{2}\left(\Delta e_{t-i}\right) & \Delta e_{t-d} \leq \gamma,\end{cases}
$$

where $\gamma$ is the threshold value of exchange rate fluctuations and also represents the transaction costs of the hedging of the gold exchange rate, while $\Delta e_{t-d}$ denotes the lag $d$-periods exchange rate returns, which is determined by the endogenous variable.

\section{Data and empirical results}

The gold prices in seven key currencies, namely the Australian dollar, Canadian dollar, euro, Indian rupee, Japanese yen, South African rand, and British pound, as well as their exchange rates with the US dollar, are selected as the research samples. The gold prices (National Currency Unit per troy ounce) are taken from the World Gold Council database and the exchange rates come from the IFS database of the International Monetary Fund. The sample period was from January 1999 to January 2010.

In order to preliminarily analyse the relationship between the discussed variables, we define two panel data variables, namely the gold returns $\left(\Delta g_{i t}\right)$ and exchange rate returns $\left(\Delta e_{i t}\right)$ of these currencies compared with US dollars, and $\mathrm{i}=1 \sim 7$. Here, $g_{i t}$ is the gold prices in these currencies; $e_{i t}$ is the exchange rates of these currencies with US dollars; and ' $\Delta$ ' represents the first-order difference. This study takes the logarithms of gold prices in these currencies and the exchange rates as the trend charts shown in Figures 3 and 4.

As seen, from January 1999 to January 2010, gold prices show a continuously rising trend. Gold prices experienced large changes from 2008 2010 in all countries, namely during and after the subprime mortgage crisis. In terms of exchange rates, the sampled currencies depreciated from 1999 2001, appreciated from 2002 2007, and experienced large changes from 2008 2010, first depreciating then appreciating, probably owing to the subprime mortgage crisis and 2008 policy of quantitative easing (QE1) in the US. By contrast, as shown in Figures 3 and 4, the relevancy of gold prices and exchange rates is different at different times: a gold rate rise and US dollar appreciation from 1999 2001 and a gold rate rise and US dollar depreciation from 2002 2008. From 2009 2010, except Japan, the relations between a gold price rise and US dollar appreciation transforms into a gold rise and US dollar depreciation. 

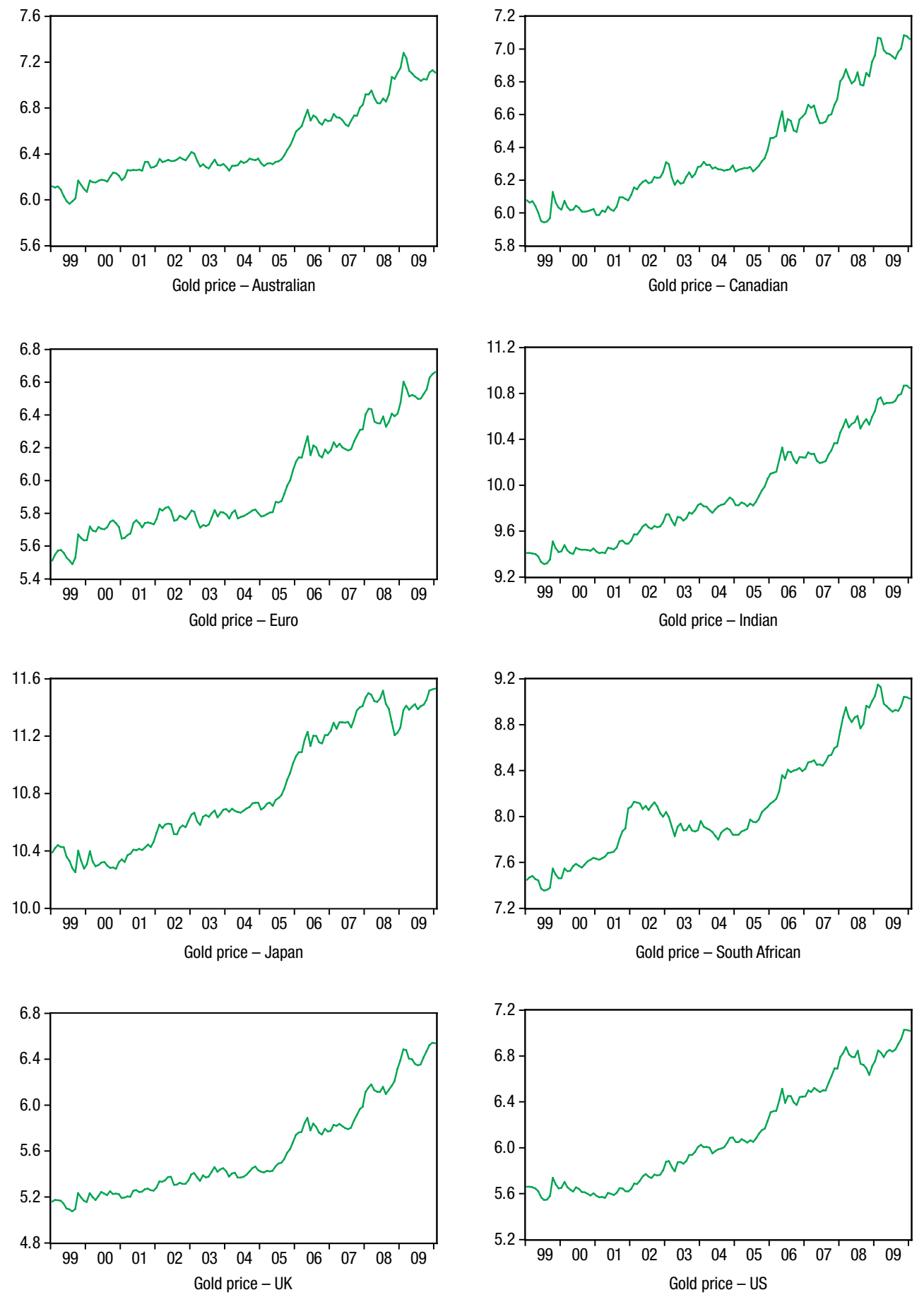

Fig. 3. The trends of the gold prices 

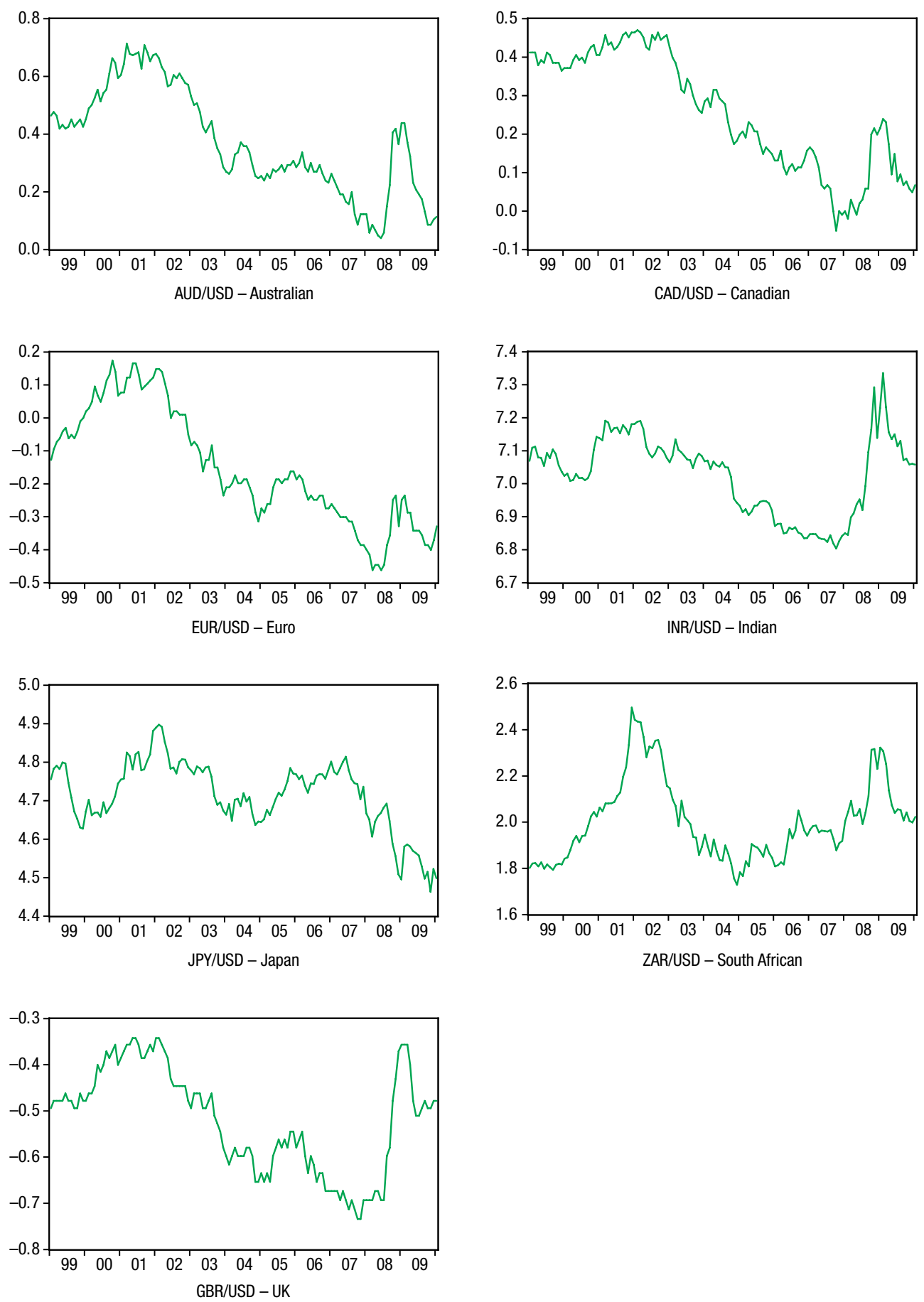

Fig. 4. The trends of the exchange rates 
Figures 5 and 6 examine the trends of gold returns and exchange rate returns. The comparison shows that in 2001 and 2008 fluctuations in gold prices and exchange rates are significant and that the movement in exchange rates is larger compared with that in gold prices.
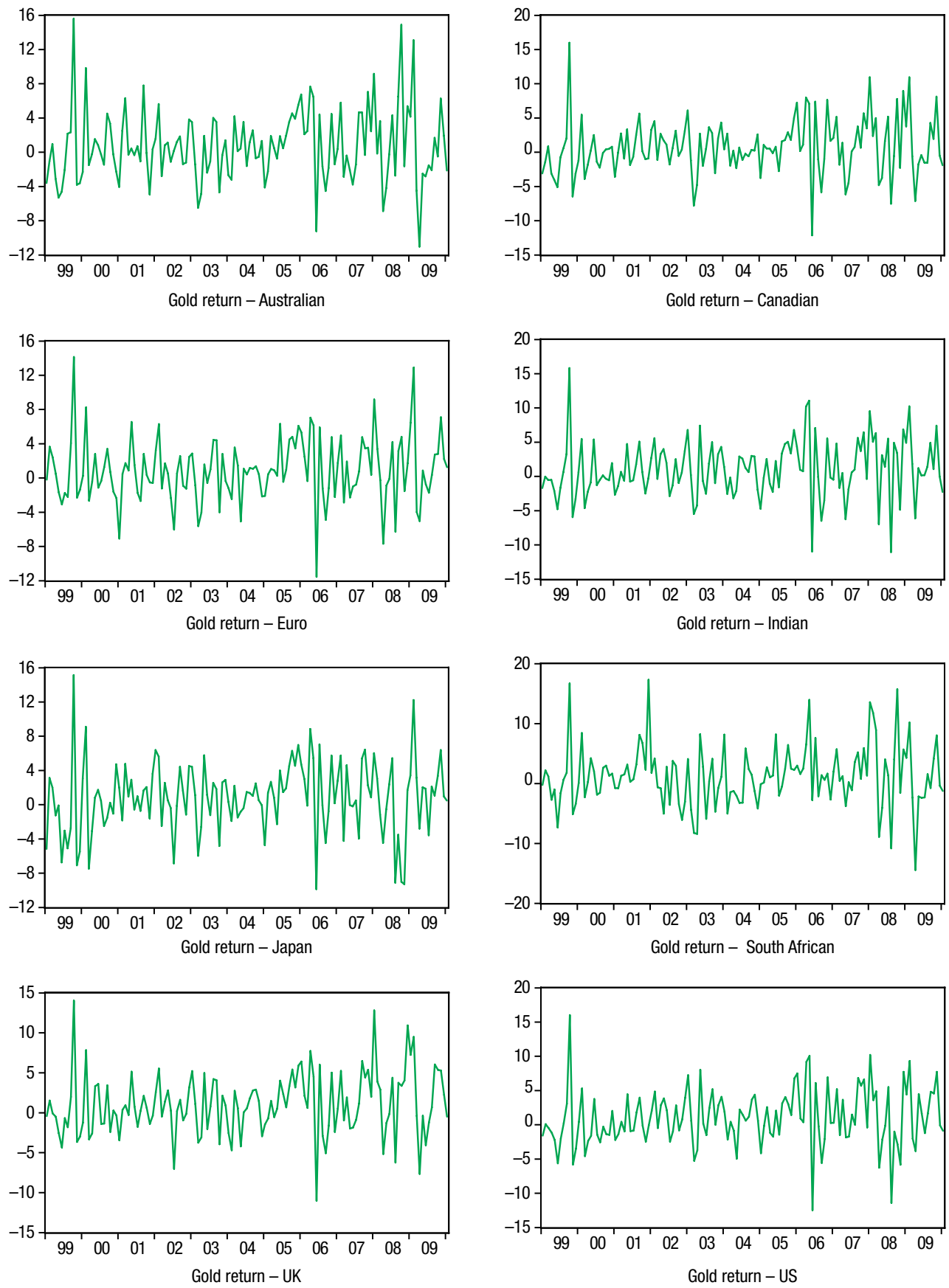

Fig. 5. The trends of the gold returns 

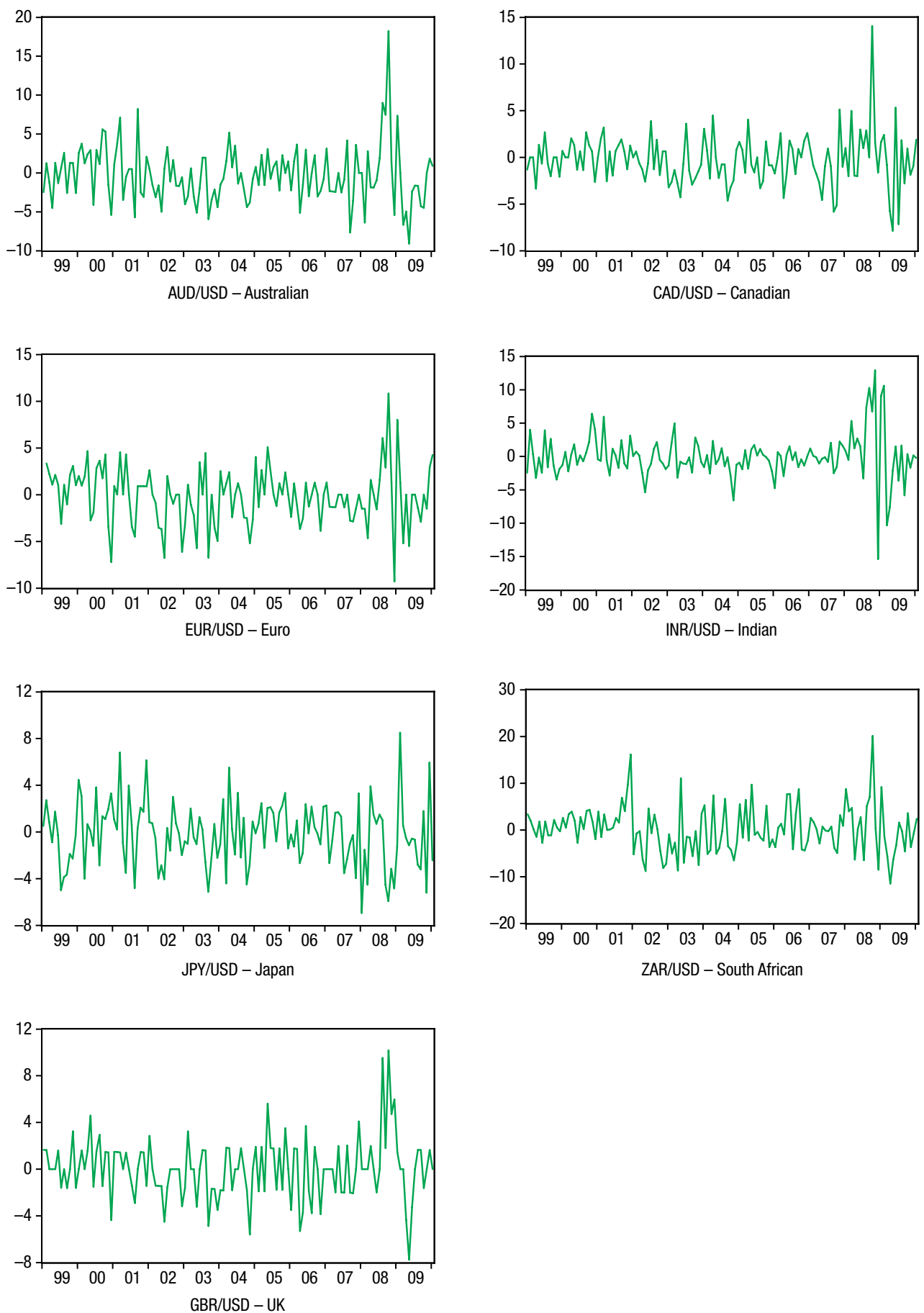

Fig. 6. The trends of the exchange rate returns 
The causes of the large fluctuations in 2001 are a series of major events, such as the September 11 attacks, global economic depression, the euro officially entering circulation, which influenced the global foreign exchange market, and the burst of the subprime mortgage crisis in 2008.

Table 1 reports the basic statistical characteristics of the panel data of gold returns and exchange rate returns. The mean value shows that during the sample period, the average return of gold is positive and that the exchanges rates of the seven currencies are depreciatory. As to the risks, the standard deviations are consistent with those shown in Figures 5 and 6, and the risks of gold returns are larger than are those of exchange rate fluctuations. In addition, the two variables show right-skewness and leptokurtic distributions. Before the model estimation, however, we must confirm whether the variables have stationary features in order to avoid spurious regressions. Table 2 reports the results of the panel unit root test. Five test methods are used, namely the Levin et al. (2002, hereafter LLC) $t^{*}$ test, Breitung (2000) t-stat test, Im et al. (2003, hereafter IPS) W-stat test, and Maddala and Wu (1999) ADF - Fisher Chi-square and PP - Fisher Chi-square tests. The results show that gold price and exchange rate returns are in a stationary state.

First, we estimate the linear panel model. In order to check the nonlinear relationship between gold returns and exchange rate returns, we add the square of exchange rate returns. The test equation is as follows:

$$
\Delta g_{i t}=\alpha_{i}+\sum_{k=1}^{n} \beta_{k} \Delta e_{i t-k}+\sum_{k=1}^{n} \gamma_{k} \Delta e_{i t-k}^{2}+\varepsilon_{i t} .
$$

Table 3 reports the estimation results of three linear models of panel data (model 1 , model 2, and model 3). The AIC criterion is used to find that lagged three-period exchange rate returns can influence gold returns. Therefore, we compare the estimation results including and excluding the square term. From the results of model 1, it is found that the exchange rate fluctuations of the lagged one-period and two-period returns

Table 1. Summary of basic statistics

\begin{tabular}{|c|c|c|}
\hline Variables & $\Delta g_{i t}$ & $\Delta e_{i t}$ \\
\hline Mean & 0.91 & -0.10 \\
\hline Median & 0.59 & 0.00 \\
\hline Maximum & 17.30 & 20.09 \\
\hline Minimum & -14.45 & -15.39 \\
\hline Std. Dev. & 4.18 & 3.39 \\
\hline Skewness & 0.36 & 0.68 \\
\hline Kurtosis & 4.58 & 6.87 \\
\hline Jarque-Bera (p-value) & $116.92(0.00)$ & $653.10(0.00)$ \\
\hline
\end{tabular}

Notes: $\Delta g_{i t}=\log \left(g_{i t} / g_{i t-1}\right) \times 100, \Delta e_{i t}=\log \left(e_{i t} / e_{i t-1}\right) \times 100 . g_{i t}-$ the gold prices in these currencies; $e_{i t}$ - the exchange rates of these currencies to US dollars. 
Table 2. Panel unit-root test

\begin{tabular}{|c|c|c|}
\hline Variables & $\Delta g_{i t}$ & $\Delta e_{i t}$ \\
\hline Method & Statistic (p-value) & Statistic (p-value) \\
\hline \multicolumn{3}{|c|}{ Null: Unit root (assumes common unit root process) } \\
\hline LLC $t^{*}$-stat & $-28.29(0.00)$ & $-32.40(0.00)$ \\
\hline Breitung t-stat & $-19.69(0.00)$ & $-19.45(0.00)$ \\
\hline \multicolumn{3}{|c|}{ Null: Unit root (assumes individual unit root process) } \\
\hline IPS W-stat & $-29.43(0.00)$ & $-28.75(0.00)$ \\
\hline ADF - Fisher Chi-square & $461.88(0.00)$ & $450.03(0.00)$ \\
\hline PP - Fisher Chi -square & $461.47(0.00)$ & $451.56(0.00)$ \\
\hline
\end{tabular}

Notes: LLC, and IPS represent the panel unit root tests of Levin et al. (2002) and Im et al. (2003), respectively. Fisher-ADF and Fisher-PP represent the Maddala and Wu (1999) Fisher-ADF and FisherPP panel unit root tests, respectively.

have a significant and positive interpretability on gold returns. Moreover, the square of exchange rate returns $\left(\Delta e_{i, t-1}^{2}\right)$ in model 2 has negative impacts on gold returns, reflecting the nonlinear relationship between exchange rate returns and gold returns and demonstrating that a linear model might not be the most suitable for capturing a nonlinear relationship. The square of the lagged two-period exchange rate returns $\left(\Delta e_{i, t-2}^{2}\right)$ in model 3 does not have significant interpretability on gold returns. Thus, in view of the results of models 1,2 , and 3 , it is known that $\Delta e_{i, t-1}$ is significant in all three models, $\Delta e_{i, t-1}^{2}$ is significant in model 2 , and $\Delta e_{i, t-1}$ is the key variable because of which the model is nonlinear.

Table 3. Estimation result of the linear panel model

\begin{tabular}{lccc}
\hline Dependent Variable: $\Delta g_{i t}$ & Model-1 & Model-2 & Model-3 \\
\hline Variable & Coefficient (p-value) & Coefficient (p-value) & Coefficient (p-value) \\
\hline Constant & $0.98(0.00)$ & $1.09(0.00)$ & $0.89(0.00)$ \\
\hline$\Delta e_{i t-1}$ & $0.28(0.00)$ & $0.30(0.00)$ & $0.28(0.00)$ \\
\hline$\Delta e_{i t-2}$ & $0.08(0.04)$ & $0.09(0.03)$ & $0.07(0.11)$ \\
\hline$\Delta e_{i t-3}$ & $0.01(0.83)$ & $0.02(0.63)$ & $0.00(0.93)$ \\
\hline$\Delta e_{i t-1}^{2}$ & & $-0.01(0.09)$ & \\
\hline$\Delta e_{i t-2}^{2}$ & & & $0.01(0.15)$ \\
\hline Akaike info criterion & 5.68 & 5.68 & 5.67 \\
\hline Schwarz criterion & 5.73 & 5.73 & 5.71 \\
\hline Log likelihood & -2570.06 & -2568.68 & -2586.72 \\
\hline
\end{tabular}


According to the results presented in Table 3, a nonlinear panel data model is built to further explain the hedging of exchange rate risks using gold. However, before constructing the nonlinear panel data model, the linearity test must be conducted. By using accurate statistical test results, this study determines whether the model has a nonlinear structure and ascertains its threshold value. This study adopts the two-stage estimation model in order to complete the DPTM process and avoid problems in the estimation process. The first-stage estimation model is the static panel threshold model (SPTM) and the second-stage estimation model is the DPTM.

According to the results shown in Table 3 , the variable $\Delta e_{i, t-1}$ may construct a nonlinear relationship for the model, so $\Delta e_{i, t-1}$ is used as the threshold variable for the linear test. Table 4 reports the linear test results of the panel data model. It is found that $\Delta e_{i, t-1}$ allows for the construction of a two-threshold SPTM between exchange rate fluctuations and gold returns (in three regimes). As a result, Hansen's (1999) PTM is used in a static structure in order to capture the nonlinear relationships between the panel data and construct a two-threshold and three-regime SPTM, as presented in equation (8):

$$
\begin{gathered}
\Delta g_{i, t}=\theta_{1} \Delta e_{i, t-2}+\theta_{2} \Delta e_{i, t-3}+\phi_{1} \Delta e_{i, t-1} I\left(\Delta e_{i, t-1} \leq \gamma_{2}\right)+ \\
\phi_{2} \Delta e_{i, t-1} I\left(\gamma_{2}<\Delta e_{i, t-1} \leq \gamma_{1}\right)+\phi_{3} \Delta e_{i, t-1} I\left(\Delta e_{i, t-1}>\gamma_{1}\right)+\varepsilon_{i, t} .
\end{gathered}
$$

The coefficients $\theta_{i}, i=1,2$ respectively represent the short-term risk-hedge parameters of lagged two-period and three-period exchange rate returns. $\varphi_{j}, j=1,2,3$ are the shortterm risk-hedge parameters of lagged one-period exchange rate returns for the three intervals respectively. $\Delta e_{i t-1}$ is the threshold variable, $\gamma_{1}$ and $\gamma_{2}$ are threshold values, and $I($.$) is the indicator function.$

Table 5 reports the estimation results of two SPTMs (models 4 and 5), where model 5 presents the estimation results of the standard deviation after heterogeneous modification.

Table 4. Likelihood ratio Test for threshold effect

\begin{tabular}{lc}
\hline \multicolumn{1}{c}{ Hypotheses } & $\mathrm{F}_{\mathrm{i}}$ statistic ( Bootstrap P-value) \\
\hline $\mathbf{H}_{\mathbf{0}}:$ Zero Threshold & $\mathrm{F}_{1}=5.26(0.00)$ \\
$\mathbf{H}_{\mathbf{1}}:$ Single Threshold & $\mathrm{F}_{2}=10.16(0.02)$ \\
\hline $\mathbf{H}_{\mathbf{0}}:$ Single Threshold & \\
$\mathbf{H}_{\mathbf{1}}:$ Double Threshold & $\mathrm{F}_{3}=0.64(0.96)$ \\
\hline $\mathbf{H}_{\mathbf{0}}:$ Double Threshold & \\
$\mathbf{H}_{\mathbf{1}}:$ Triple Threshold & \\
\hline
\end{tabular}

Notes: The threshold variable is $\Delta e_{i, t-1}$. The likelihood ratio (LR) testing for a threshold is based on the statistic $\mathrm{F} 1$ (test for single threshold). The asymptotic distribution of $\mathrm{F}_{1}$ is non-standard, and strictly dominates the $\chi^{2}$ distribution. Because $\mathrm{F}_{1}$ rejects the null of no threshold, a further tests to discriminate between one and two thresholds. Thus an approximate likelihood ratio test of one versus two thresholds based on the statistic $\mathrm{F}_{2}$ (test for double threshold). Because $\mathrm{F}_{2}$ rejects the null of one threshold, then the statistic $\mathrm{F}_{3}$ (test for triple threshold), an approximate likelihood ratio test of two versus three thresholds (see Hansen 1999). Because $F_{1}$ and $F_{2}$ are significant but $F_{3}$ is not, which indicates that there are two threshold points. 
Table 5. Estimation result of the static panel threshold model

\begin{tabular}{lcc}
\hline \multicolumn{1}{c}{ Dependent Variable: $\Delta g_{i t}$} & \multicolumn{2}{c}{ Model-4 Model-5 } \\
\hline Variable & Coefficient (p-value) & Coefficient (p-value) \\
\hline$\Delta e_{i t-2}$ & $0.083(0.04)$ & $0.083(0.07)$ \\
\hline$\Delta e_{i t-3}$ & $0.006(0.87)$ & $0.006(0.88)$ \\
\hline$\Delta e_{i t-1} I\left(\Delta e_{i t-1} \leq-7.5 \%\right)$ & $0.043(0.72)$ & $0.043(0.73)$ \\
\hline$\Delta e_{i t-1} I\left(-7.5 \%<\Delta e_{i t-1} \leq-3.7 \%\right)$ & $0.559(0.00)$ & $0.559(0.00)$ \\
\hline$\Delta e_{i t-1} I\left(\Delta e_{i t-1}>-3.7 \%\right)$ & $0.222(0.00)$ & $0.222(0.00)$ \\
\hline
\end{tabular}

Note: The threshold variable is $\Delta e_{i, t-1}$.

It is estimated that the SPTM has two threshold (values), namely $\gamma_{1}=-3.7 \%$ and $\gamma_{2}=$ $-7.5 \%$; we thus divide the model into three regimes, namely regime $1\left(\Delta e_{i t-1} \leq-7.5 \%\right)$, regime $2\left(-7.5 \%<\Delta e_{i t-1} \leq-3.7 \%\right)$, and regime $\left.3\left(-3.7 \%<\Delta e_{i t-1}\right)\right)$. The estimation results of the nonlinear part of Table 5 are similar to those of the linear model in Table 3. Only the lagged second-period exchange rate returns $\left(\Delta e_{i t-2}\right)$ have a significant interpretability on gold returns. Furthermore, when the threshold variable is smaller than is the second threshold value $(-7.5 \%)$ (in regime 1 ), the exchange rate fluctuation does not have a significant interpretability on gold returns and its estimation coefficient is the smallest. If the US dollar is depreciated excessively against other currencies, gold cannot hedge the exchange rate risks. In regimes 2 or 3, the exchange rate fluctuation has a significant interpretability on gold returns, reflecting that gold can hedge exchange rate risks. The gold hedging against the US dollar depreciation in regime 2 has a better effect (estimation coefficient of 0.559) than does that in regime 3 (estimation coefficient of 0.222). This means that the more the US dollar depreciates, the larger the hedge effect of gold. However, if the degree of depreciation is too acute, thus causing an overshooting of the short-term exchange rate, gold hedging cannot be realized.

The second-stage dynamic model links to the estimation result of the first-stage nonlinear model. This paper sets three intervals using dummy variables. The estimation process adopts Arellano and Bond's (1991) GMM as discussed, and the DPTM in this paper is as presented in equation (9). Furthermore, the variable $\Delta e_{i, t-1}^{2}$ is again added in order to compare with equation (10). We estimate the DPTM as follows:

$$
\begin{gathered}
\Delta g_{i t}=\alpha \Delta g_{i t-1}+\theta_{1} \Delta e_{i, t-2}+\theta_{2} \Delta e_{i, t-3}+\phi_{1} \Delta e_{i, t-1} d u m_{1}\left(\Delta e_{i t-1} \leq-7.5 \%\right)+ \\
\phi_{2} \Delta e_{i, t-1} d u m_{2}\left(-7.5 \%<\Delta e_{i t-1} \leq-3.7 \%\right)+\phi_{3} \Delta e_{i, t-1} d u m_{3}\left(\Delta e_{i t-1}>-3.7 \%\right)+\varepsilon_{i t}, \\
\Delta g_{i t}=\alpha \Delta g_{i t-1}+\theta_{1} \Delta e_{i, t-2}+\theta_{2} \Delta e_{i, t-3}+\theta_{3} \Delta e_{i, t-1}^{2}+\phi_{1} \Delta e_{i, t-1} d u m_{1}\left(\Delta e_{i t-1} \leq-7.5 \%\right)+ \\
\phi_{2} \Delta e_{i, t-1} d u m_{2}\left(-7.5 \%<\Delta e_{i t-1} \leq-3.7 \%\right)+\phi_{3} \Delta e_{i, t-1} d u m_{3}\left(\Delta e_{i t-1}>-3.7 \%\right)+\varepsilon_{i t},
\end{gathered}
$$

where $\alpha, \theta, \varphi$ are estimation coefficients and dum is a dummy variable for distinguishing different regimes. 
Table 6 reports the estimation result of the DPTM. In the dynamic estimation, lagged one-period gold returns have significant influencing power. In the short-term in regimes 2 and 3, the exchange rate fluctuation has significant impacts on gold returns and thus gold returns can be used to hedge exchange rate risks (the effect of regime 2 is better than is that of regime 3). The estimation results of regime 1 are the same as those presented in Table 5, namely if the US dollar is depreciated too much, gold cannot hedge exchange rate risks. From the results of model 7 in Table 6, it is found that the square of lagged one-period exchange rate returns does not have a significant influencing power over gold returns. Through nonlinear estimation, the influencing power of $\Delta e_{i, t-1}^{2}$ of model 2 in Table 3 is thus replaced.

Table 6. Estimation result of the dynamic panel threshold model (Arellano and Bond GMM method)

\begin{tabular}{lcc}
\hline \multicolumn{1}{c}{ Dependent Variable: $\Delta g_{i t}$} & Model-6 & Model-7 \\
\hline Variable & Coefficient (p-value) & Coefficient (p-value) \\
\hline$\Delta g_{i t-1}$ & $-0.051(0.000)$ & $-0.044(0.000)$ \\
\hline$\Delta e_{i t-2}$ & $0.131(0.02)$ & $0.139(0.01)$ \\
\hline$\Delta e_{i t-3}$ & $0.038(0.18)$ & $0.046(0.125)$ \\
\hline$\Delta e_{i t-1}^{2}$ & & $-0.015(0.25)$ \\
\hline$\Delta e_{i t-1} d u m_{1}\left(\Delta e_{i t-1} \leq-7.5110\right)$ & $-0.052(0.71)$ & $-0.179(0.24)$ \\
\hline$\Delta e_{i t-1} d u m_{2}\left(-7.5110<\Delta e_{i t-1} \leq-3.6692\right)$ & $0.644(0.00)$ & $0.573(0.00)$ \\
\hline$\Delta e_{i t-1} d u m_{3}\left(\Delta e_{i t-1}>-3.6692\right)$ & $0.131(0.01)$ & $0.233(0.039)$ \\
\hline Sum squared residual & 28498.81 & 28285.26 \\
\hline Instrument rank & 376 & 376 \\
\hline J-statistic $(\mathrm{p}$-value) & $414.01(0.10)$ & $410.55(0.131)$ \\
\hline \hline
\end{tabular}

Wald Test:

\begin{tabular}{lcl}
\hline Null hypothesis & $\begin{array}{c}\text { Chi-square } \\
\text { statistic (p-value) }\end{array}$ & Testing results \\
\hline$H_{10}: \theta_{1}+\theta_{2}<0$ & $5.324(0.021)$ & Gold is a hedge for exchange rates (dollars) \\
\hline$H_{20}: \theta_{1}+\theta_{2}+\phi_{1}<0$ & $0.467(0.494)$ & gold is not a safe haven for exchange rates (dollars) \\
\hline$H_{30}: \theta_{1}+\theta_{2}+\phi_{2}<0$ & $25.54(0.000)$ & gold is a safe haven for exchange rates (dollars) \\
\hline$H_{40}: \theta_{1}+\theta_{2}+\phi_{3}<0$ & $12.14(0.001)$ & gold is a safe haven for exchange rates (dollars) \\
\hline
\end{tabular}

Notes: The estimation process adopts Arellano and Bond's (1991) Generalized Method of Moments, and the DPTM in this paper is as presented in Eq. (9) of Model-6. On the other hand, the variable $\Delta e_{i, t-1}^{2}$ is added again to compare Eq. (10) of Model-7. The Instrument rank and J-statistic be used to construct the Sargan's Chi-square statistic. These are designed to test the null hypothesis of overidentifying restriction. 
Since a long-term co-integration relationship does not exist, in order to estimate the long-term effect of gold hedging, we utilize three formulas to estimate the long-term hedging parameters in three regimes: $\delta_{1}=\frac{\theta_{1}+\theta_{2}+\phi_{1}}{1-\alpha}=, \delta_{2}=\frac{\theta_{1}+\theta_{2}+\phi_{2}}{1-\alpha}$ and $\delta_{3}=\frac{\theta_{1}+\theta_{2}+\phi_{3}}{1-\alpha}$. According to the estimation results of model 6 in Table 6 , we calculate the long-term hedge parameters in three different regimes, namely $\delta_{1}^{\text {model } 6}=0.111$, $\delta_{2}^{\text {model } 6}=0.773$ and $\delta_{3}^{\text {model } 6}=0.285$. According to the results of model 7 , we find $\delta_{1}^{\text {model } 7}=0.005, \delta_{2}^{\text {model } 7}=0.726$ and $\delta_{3}^{\text {model } 7}=0.400$. For analytical convenience, Figure 7 is used to provide a description. According to the slope, the hedge effect of regime 2 is the largest, followed by that of regime 3 and regime 1 . This implies that regime 1 does not have a significant hedge effect in the short-term, because its long-term hedge effect is small when the US dollar is overly depreciated. Because of its weak long-term hedge effect, short-term gold hedging does not exist for investors.

We further discuss whether in the short-term gold is a hedge or a safe haven. Baur and Lucey (2010) used different quantiles of independent variables in order to simulate extreme events and to test whether gold is a safe haven. By contrast, the threshold division method of this study is endogenous from the model and thus it fully reflects the three structural changes in exchange rate fluctuations. This method can also show the impacts of these structural changes at different time points. Consequently, we set up four null hypotheses according to the division of the three regimes from equation (9):

$H_{10}: \theta_{1}+\theta_{2}<0$ Gold is a hedge for exchange rates (US dollar).

$H_{20}: \theta_{1}+\theta_{2}+\phi_{1}<0$ Gold is a safe haven for exchange rates (US dollar) in regime 1. $H_{30}: \theta_{1}+\theta_{2}+\phi_{2}<0$ Gold is a safe haven for exchange rates (US dollar) in regime 2. $H_{40}: \theta_{1}+\theta_{2}+\phi_{3}<0$ Gold is a safe haven for exchange rates (US dollar) in regime 3. The results of the Wald test are reported in Table 6 . From the test results of the statistical values of the Chi-square test, we can conclude that gold is a hedge for exchange rates and that gold is a safe haven for exchange rates in regimes 2 and 3, but not in

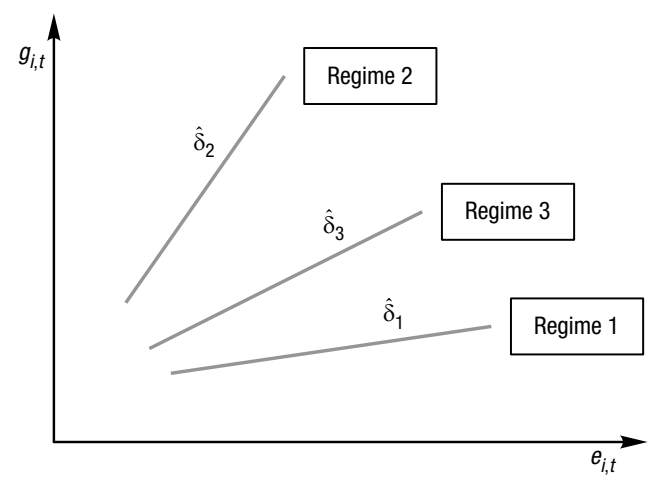

Fig. 7. The long-term hedge coefficients in three regimes 
regime 1. The results of this paper are thus in line with the method suggested by Baur and Lucey (2010), namely that gold is a hedge for exchange rates; however, in regime 1 , where the US dollar is overly depreciated (or a bubble in gold price occurs), gold is not a safe haven for exchange rates.

\section{Discussions and implications}

The empirical results of this study indicate that gold can hedge exchange rate risks. However, in the case of the excessive depreciation of the US dollar (by $-7.5 \%$ or lower), the safe haven effect of gold disappears. In this case, gold is not a safe haven for exchange rates (dollars) under the approach of Baur and Lucey (2010). From a theoretical point of view, Park (1987) argued that the existence of currency substitution was the major reason for overshooting. This paper suggests that the hedging function of gold can also be replaced by foreign currencies and thus the safe haven characteristic of gold disappears. Isaac (1998) argued that the risk premiums arising from the impact of monetary policy were another reason for exchange rate overshooting if exchange rate fluctuations were outside a tolerable range of economic fundamentals. However, Dornbusch (1976) explained that exchange rate overshooting was caused by the impact of monetary policy.

We suggest that as the risk premium grows compared with the positive premium of gold returns, the safe haven characteristic of gold disappears consequentially. By contrast, Bjørnland (2009), from an empirical point of view, believed that the long-run neutrality restriction of exchange rates was the reason for the authenticity of Dornbusch's exchange rate overshooting hypothesis because the interest rate would simultaneously change with the exchange rate. This study suggests that when the interest rate responds to the exchange rate, the hedging characteristic of gold disappears, resulting in exchange rate overshooting and invalidating the gold hedging characteristic.

In summary, this study used DPTM analysis to assess the mutual impact of the common trend between gold and key currencies in the world in order to fully understand the hedging characteristic of gold. It found that exchange rate returns affect gold hedging capability and that the proposed model had two thresholds and three regimes owing to dollar depreciation. This may affect the short-term and long-term hedging capability of gold and its characteristic as a safe haven. This study also found that the hedging effect of gold reverses and becomes non-significant during exchange rate depreciation (for exchange rate returns lower than $-7.5 \%$ ). Regarding the reason for the disappearance of the hedging characteristic of gold, we explained the long-term hedging coefficient and the overshooting point of view.

\section{Conclusions}

Previous studies of whether gold can effectively avoid exchange rate risks have usually analysed the relationship between a single currency and gold prices by individual country using time series data. Compared with other studies, this paper makes the following contributions. First, from a research viewpoint, it used the panel threshold regression method to determine the efficiency of exchange rate hedging using gold in order to test 
whether gold is a safe haven. Second, because the regime conversion arising from exchange rate fluctuations influences the effect of gold exchange rate hedging, this study did not establish an asymmetrical DPTM. The major economic implication of this was that changes reflected by exchange rate fluctuations had an endogenous impact. Only if the indigenized impact is taken into consideration can international investors' hedging strategies be feasible and effective. This finding is one of the major contributions of this paper. Finally, we found that if there is excessive depreciation in the exchange rate (or in US dollars), the gold hedging effect reverses and becomes not significant as well as not a safe haven. The reasons for the disappearance of the gold hedging characteristic in the exchange rate excessive depreciation range can be explained by the long-term hedging effect and from the perspective of the overshooting viewpoint. These new methods and viewpoints have not been used to explain the relationship between gold prices and the exchange rate in previous studies.

\section{References}

Arellano, M.; Bond, S. 1991. Some tests of specification for panel data: Monte Carlo evidence and an application to employment equations, Review of Economic Studies 58: 277-297.

http://dx.doi.org/10.2307/2297968

Arellano, M.; Bover, S. 1995. Another look at the instrumental-variable estimation of errorcomponents models, Journal of Economics 68: 29-51.

Baker, S. A.; Tassel, van R. C. 1985. Forecasting the price of gold: a fundamentalist approach, Atlantic Economic Journal 13: 43-51. http://dx.doi.org/10.1007/BF02304036

Baur, D.; Lucey, B. M. 2010. Is gold a hedge or a safe haven? An analysis of stocks, bonds and gold, The Financial Review 45(2): 217-229. http://dx.doi.org/10.1111/j.1540-6288.2010.00244.x

Bjørnland, H. C. 2009. Monetary policy and exchange rate overshooting: Dornbusch was right after all, Journal of International Economics 79(1): 64-77.

http://dx.doi.org/10.1016/j.jinteco.2009.06.003

Breitung, J. 2000. The local power of some unit root tests for panel data, in B. Baltagi (Ed.). Advances in Econometrics, Vol. 15: Nonstationary panels, panel cointegration, and dynamic panels. Amsterdam: JAI Press, 161-178.

Capie, F.; Mills, T. C.; Wood, G. 2005. Gold as a hedge against the dollar, Journal of International Financial Markets, Institutions and Money 15: 343-352.

http://dx.doi.org/10.1016/j.intfin.2004.07.002

Clements, K. W.; Fry, R. 2008. Commodity currencies and currency commodities, Resources Policy 33(2): 55-73. http://dx.doi.org/10.1016/j.resourpol.2007.10.004

Dooley, M. P.; Isard, P.; Taylor, M. P. 1995. Exchange rates, country-specific shocks and gold, Applied Financial Economics 5: 121-129. http://dx.doi.org/10.1080/758522999

Dornbusch, R. 1976. Expectations and exchange rate dynamics, Journal of Political Economy 84(6): 1161-1176. http://dx.doi.org/10.1086/260506

Hansen, B. E. 1999. Threshold effects in non-dynamic panels: estimation, testing, and inference, Journal of Econometrics 93(2): 345-368. http://dx.doi.org/10.1016/S0304-4076(99)00025-1

Im, K. S.; Pesaran, M. H.; Shin, Y. 2003. Testing for unit roots in heterogeneous panels, Journal of Econometrics 115: 53-74. http://dx.doi.org/10.1016/S0304-4076(03)00092-7

Isaac, A. G. 1998. Risk premia and overshooting, Economics Letters 61(3): 359-364.

http://dx.doi.org/10.1016/S0165-1765(98)00191-8

Joy, M. 2011. Gold and the US dollar: hedge or haven?, Finance Research Letters 8(3): 120-131.

http://dx.doi.org/10.1016/j.frl.2011.01.001 
Kolluri, B. R. 1981. Gold as a hedge against inflation: an empirical investigation, Quarterly Review of Economics and Business 21: 13-24.

Koutsoyiannis, A. 1983. A short-run pricing model for a speculative asset, tested with data from the gold bullion market, Applied Economics 15: 563-581.

http://dx.doi.org/10.1080/00036848300000037

Kyrtsou, C.; Labys, W. 2006. Evidence for chaotic dependence between U.S. inflation and commodity prices, Journal of Macroeconomics 28: 256-266.

http://dx.doi.org/10.1016/j.jmacro.2005.10.019

Laurent, R. D. 1994. Is there a role for gold in monetary policy?, Economic Perspectives 18: $2-14$.

Levin, A.; Lin, C. F.; Chu, C. 2002. Unit root tests in panel data: asymptotic and finite-sample properties, Journal of Econometrics 108: 1-24. http://dx.doi.org/10.1016/S0304-4076(01)00098-7

Maddala, G. S.; Wu, S. 1999. A comparative study of unit root tests with panel data and a new simple test, Oxford Bulletin of Economics and Statistics 61: 631-652.

http://dx.doi.org/10.1111/1468-0084.61.s1.13

Mahdavi, S.; Zhou, S. 1997. Gold and commodity prices as leading indicators of inflation: tests of long-run relationship and predictive performance, Journal of Economics and Business 49: 475-489. http://dx.doi.org/10.1016/S0148-6195(97)00034-9

Moore, G. 1990. Gold prices and a leading index of inflation, Challenge 33: 52-56.

Park, W.-A. 1987. Crawling PEG, inflation hedges, and exchange rate dynamics, Journal of International Economics 23: 131-150. http://dx.doi.org/10.1016/S0022-1996(87)80009-0

Pindyck, R. S. 1993. The present value model of rational commodity pricing, The Economic Journal 103: 511-530. http://dx.doi.org/10.2307/2234529

Pukthuanthong, K.; Roll, R. 2011. Gold and the Dollar (and the Euro, Pound, and Yen), Journal of Banking and Finance 35(8): 2070-2083. http://dx.doi.org/10.1016/j.jbankfin.2011.01.014

Sjaastad, L. A.; Scacciallani, F. 1996. The price of gold and the exchange rate, Journal of Money and Finance 15: 879-897. http://dx.doi.org/10.1016/S0261-5606(96)00045-9

Sjaastad, L. A. 2008. The price of gold and the exchange rates: once again, Resources Policy 33: 118-124. http://dx.doi.org/10.1016/j.resourpol.2007.10.002

Wang, K. M.; Lee, Y. M. 2011. The yen for gold, Resources Policy 36: 39-48.

http://dx.doi.org/10.1016/j.resourpol.2010.06.002

Wang, K. M.; Lee, Y. M.; Nguyen Thi, T. B. 2011. Time and place where gold acts as an inflation hedge: an application of long-run and short-run threshold model, Economic Modelling 28: 806-819. http://dx.doi.org/10.1016/j.econmod.2010.10.008

Worthington, A. C.; Pahlavani, M. 2006. Gold investment as an inflationary hedge: cointegration evidence with allowance for endogenous structural breaks, in P. Basu, G. O'Neill, A. Travaglione (Eds.). 3rd International Conference on Contemporary Business Conference Proceedings. Wagga Wagga: Faculty of Commerce, Charles Stuart University, 1-13.

Kuan-Min WANG. Professor of Finance, Overseas Chinese University. Wang's areas of expertise are in international finance, financial markets, and econometrics for finance. Wang's academic publications have appeared in several journals including Economic Modelling, Applied Economics, Quality \& Quantity, Transformations in Business \& Economics, Expert Systems With Applications, International Journal of Business and Economics, Quantitative Finance, and Resources Policy. 